\title{
Scientific Explanation of Negative Impact of Seating on Learning
}

\author{
${ }^{1}$ M. Y. Mafuyai, ${ }^{2}$ B. G. Babangida, ${ }^{3}$ Kaburuk, S. D, ${ }^{4}$ M. Mankilik, ${ }^{5}$ Y. Y. Jabil \\ ${ }^{1,5 .}$ Physics Department, University of Jos, PMB 2084 Jos. \\ 2. Department of Mathematics, Kaduna State College of Education, Gidan Waya. \\ ${ }^{3 .}$ Department of Psychology, University of Jos. \\ 4. Department of sci. \& Tech. Education, University of Jos.
}

\begin{abstract}
In this work, the psychological effect of stress on the brain and human cognitive has been reviewed and the stress created by seating posture is explained. Its negative impact on learning is pointed out. The recently most favoured seating posture and device have been scientifically criticized. Some natural observations that validate the explanation of how seating creates stress have been enumerated and suggestion is made for school seats to be specially designed so as to reduce the stress created by seating for a long period of time and enhance concentration.
\end{abstract}

\section{Introduction}

'It is said that when one stop learning, one must have come to the end of one's life'. This important and necessary aspect of living is organized into formal and non-formal process. It is a useful tool for nature exploration and transfer of values and heritage from one generation to another. It is as old as man himself and despite its long history of existence, there are still challenges confronting learning. One of such challenges which seem to affect every learner is the challenge posed by seating. Researches on both seating arrangement and seating posture have shown that seating can affect learning (Karen,2011;Holly et al, 2007; Clapp' 2006; Alexandra et al, 2006;Stires, 1980). This work takes a look into this problem by reviewing how tress affects the brain and human cognitive, how concentration is loss due to stress, how seating can lead to increase or decrease in stress and finally suggested how to minimized the stress and enhance concentration which in turn improves learning.

\section{Method}

\section{Review of Stress effects on brain and cognitive}

Oxford Dictionary defines stress as: 1. pressure or tension exerted on a material object, 2. a state of mental or emotional strain or tension resulting from adverse or demanding circumstances. Melinda etal (2013) said stress is a normal physical response to events that make you feel threatened or upset your balance in some way. Defining stress becomes a subject of controversy for many decades. The difficulty in defining this phenomenon was first appreciated by Hans Selye (1907-1982) in 1926. In 1951, Selye's view of stress was loosely summarized by a commentator as something that "...in addition to being itself, was also the cause of itself, and the result of itself" (Hans, 1956; Humphrey, 2005) .First to use the term in a biological context, Selye continued to define stress as "the non-specific response of the body to any demand placed upon it". As of 2011 neuroscientists such as Bruce McEwen and Jaap Koolhaas believe that stress, based on years of empirical research, "should be restricted to conditions where an environmental demand exceeds the natural regulatory capacity of an organism"(Koolhaas, 2011). Melinda etal (2013) said Psychologist Connie Lillas uses a driving analogy to describe the three most common ways people respond when they're overwhelmed by stress:

- Foot on the gas - An angry, agitated, or "fight" stress response. You're heated, keyed up, overly emotional, and unable to sit still.

- Foot on the brake - A withdrawn, depressed, or "flight" stress response. You shut down, pull away, space out, and show very little energy or emotion.

- Foot on both - A tense or "freeze" stress response. You become frozen under pressure and can't do anything. You look paralyzed, but under the surface you're extremely agitated.

Despite the challenge of defining stress, one thing that remains clear is that the symptoms can be classified as cognitive, emotional, physical or behavioral. Of interest to this research are the cognitive symptoms which include: Memory problems, Inability to concentrate, Poor judgment, seeing only the negative, Anxious or racing thoughts and Constant worrying (Melinda etal, 2013). Researches have shown unarguable link between stress and brain (McEwen and Morrison, 2013;Arnsten, 2009)

The brain is the processing unit of human memory. Eric R Kandel (2013) said 'The human brain weighs only three pounds, and it looks simple enough. But it is the most complex object in the universe. This remarkable organ is responsible for everything from our simplest automatic behaviors like breathing to our most 
complex cognitive acts of thought, planning, and creativity'. Brain development goes through sensitive periods during which stress and nurturing experiences can have lasting effects. The brain is central to stress and adaptation because it perceives possible danger and determines behavioral responses, ranging from fighting or fleeing, to vigilance and anxiety. The brain also determines health damaging behaviors such as eating too much, smoking or drinking, and sleeping badly. Through the nervous system, the brain also regulates the body's hormonal, immune and metabolic processes that can affect many body processes at once. In turn, the hormones responsible for stress, sex, and metabolism affect the brain; they can alter the structure of neurons and their connections, influence behavior and even change the hormonal processes themselves. For example, chronic stress can increase anxiety and decrease memory and cognitive flexibility (Bruce, 2011).In recent years it has been established that in addition to already familiar LTP (long-term potentiation), we also have LTD (long-term depression) (Leon,2013).

Chronic over-secretion of stress hormones adversely affects brain function, especially memory. Too much cortisol can prevent the brain from laying down a new memory, or from accessing already existing memories. Also, neurons in the parts of the brain relating to learning, memory and judgment don't function as well under stress. Extreme or sustained stress can damage the brain's hippocampus, making it difficult to learn new things. Animal research at the University of South Florida found that stressed rats continuously explored their surroundings, as if they had no ability to retain memory (Stanford Report, 2007; The Franklin Institute, 2014). Stress is caused by conditions called stressors. Stressors have physical, chemical and mental responses inside of the body. Physical stressor produce mechanical stresses on skin, bones, ligaments, tendons, muscles and nerves that cause tissue deformation and in extreme cases tissue failure. Chemical stresses also produce biomechanical responses associated with metabolism and tissue repair. Physical stressors may produce pain and impair work performance (NRC 2001, NRC 1999).

\section{Review Of Factors Influencing Learning}

Factors that influence learning; factors such as poverty and malnutrition negatively affect the psychosocial and cognitive development of the child. In addition, classes continue to be too large, there is a constant lack of educational materials, teachers are not appropriately trained, curricula are not well adapted to the different multicultural contexts, schools are poorly supervised, and many children are still relegated to environments that discourage learning. All of these factors together have resulted in a negative impact on student performance and learning achievement levels (UNESCO, 2007). Other factors which can come from the student, teacher or both include: Motivation, Aptitude, presentation, repetition, practice with reinforcement, clarity, Task orientation, student opportunity, Variety, Teacher enthusiasm, metacognition, mental modeling, spacing, repeated testing etc.(CNC, 2014, Jim flower 2006, CUGSASTC, 2014). Stress has been shown to affect concentration which is keyed to learning any subject matter. Our ability to concentrate depends on factors such as commitment, enthusiasm for the task, skill at doing the task, our emotional and physical state, our psychological state, our environment. Minimizing this can be much easier for adult students who have purposefully seek admission to study a course of interest but not kids and teens whose minds must be deceived into believing that the material being taught them has any value to their lives and the society ( UCS 2013, CCU, 2012). Researches aimed at improving concentration have in recent time seems to favour the use of therapy ball or ball chairs (Figure 1) as an alternative to the normal class room chair. This theory is based on the fact that the ball is less stable and hence students tend to direct their natural kinesthetic energy and need for movement in a positive way, because the child on a ball chair has to constantly move his body on the chair to maintain his balance (Einas et al, 2013; Wen-Lan et al, 2012; Karen, 2011). However, what these works fail to show is what causes the loss of concentration; they rather focus on the improvement.
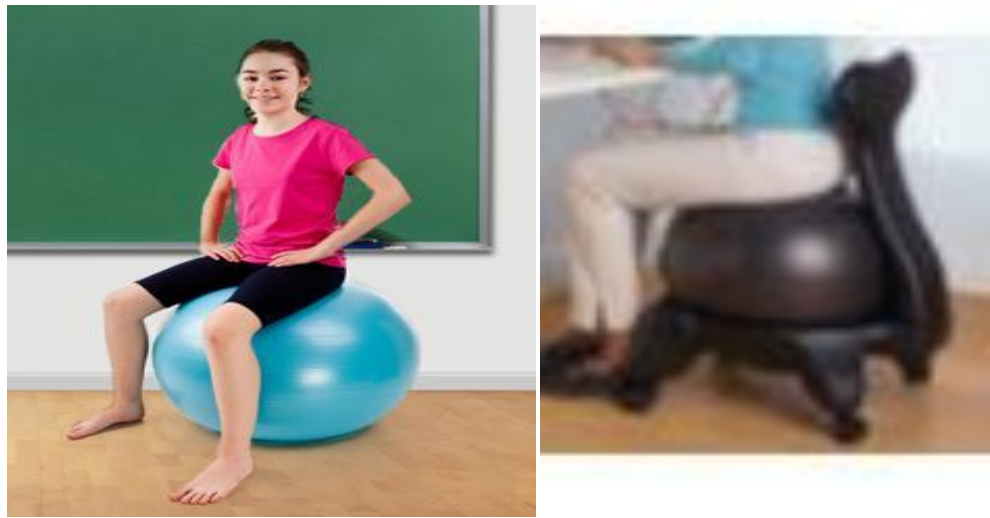

Figure 1 A Therapy Ball And Classical Balance Ball Chair.(Karen, 2011) 


\section{Discussion}

Definition; For the purpose of this work, we defined stress as the pressure or tension exerted on a person thereby resulting in a mental misbalance

\section{Best Sitting Posture}

There has been a debate among researchers on what the best seating posture is. While others favour upright sitting posture, others are of the opinion that sitting at $135^{\circ}$ between the thigh and the spine. Yet others prefer slouching. The argument is based on the impact of the seating position on the inter-vertebral disc (see the Figure 2for slouching, upright and $135^{\circ}$ ) (Su, 2011; Belle 2013, Brett 2011, OSHA 2014, Sondra etal 2014)

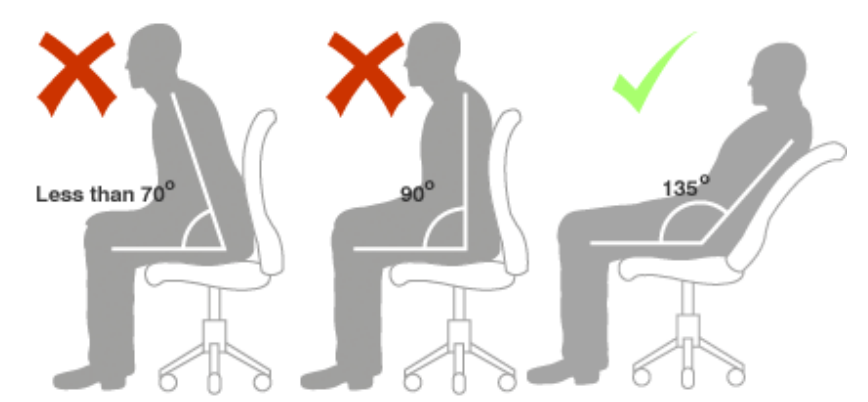

Figure 2. Seating Positions (Su, 2011)

Mafuyai etal (2013) shows that three postures of the lumbar spine are common: Neutral, Concave (lordoses) and convex (flexion) (see Figure 3). At neutral posture, the spine bears only the true weight of the body. The concave posture increase the weight borne by the lumbar spine while the convex posture decreases the weight by a quantity called virtual weight given by equation 1

$$
\mathrm{W}_{\mathrm{v}}=\left(\frac{\mathrm{d}}{\mathrm{d}_{\mathrm{N}}}-1\right) \mathrm{W}_{\mathrm{t}}
$$

Where $d$ is the moment arm at other posture of the lumbar spine and $d_{N}$ is the moment arm at neutral posture. Therefore, the extent to which a seating position becomes best depends on what posture of the spine resulted thereof. The angle between the thigh and the spine has less to do with the stress experience by the intervertebral disc, unless it alters the shape of the lumbar spine, but can affect blood circulation.

\section{Therapy Ball Theory}

Scientifically, the success of the therapy ball in improving concentration may not be due to the instability of the ball which necessitates the students to direct their natural kinesthetic energy and need for movement in a positive way, but could be due to the cushioning effect of the ball which reduces the reaction that would occur at the intervertebral disc according to Newton's third law of motion. The less the reaction the less the pain experience at the lower back and hence less fidgeting and more concentration during lessons ( Mafuyai et al, 2013 ${ }^{\mathrm{a}}$ )

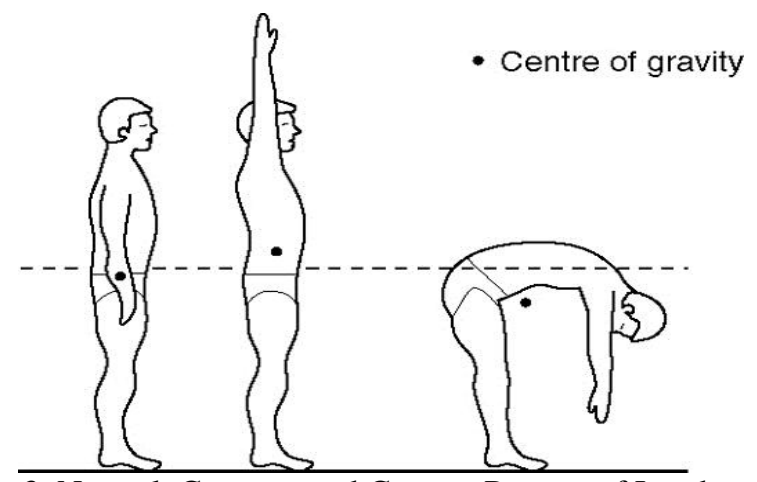

Figure 3. Neutral, Concave and Convex Posture of Lumbar Spine

The increase or reduction in stress experienced by the intervertebral disc at different posture of the lumbar spine is given by

$$
\mathrm{S}_{\mathrm{v}}=\left(\frac{\mathrm{d}}{\mathrm{d}_{\mathrm{N}}}-1\right) \frac{\mathrm{W}_{\mathrm{t}}}{\mathrm{A}_{0} \cos \theta}
$$


Where $A_{0}$, is the original surface area of the vertebra under consideration and $\theta$ is the tilting angle

Mafuyai attributed the natural bending forward at old age to the reduction in stress experience at convex posture while the great stress experience by pregnant and obese people is attributed to the increase in stress due the concave posture. Before the 2006 research findings of $135^{\circ}$ seating position and even after, the widely favoured seating position is upright (see Figure 4), this is because it has been widely believed that the lumbar curve (concave) reduces pressure from the intervertebral disc (Mafuyai et al 2013 ${ }^{\mathrm{a}, \mathrm{b}, \mathrm{c}}$, Mafuyai et al 2014, Asai, 2013;Chair Clinic,2014; CUE, 2014 ). However, research findings have invalidated this claim. And careful examination will show that this position-the upright sitting position produces a concave posture on the lumbar spine which, according to the recent findings, results in an increased stress on the lower back. This is the reason for the serious fatigue and loss of concentration from learners during afternoon lecture periods haven sat for long period of time.

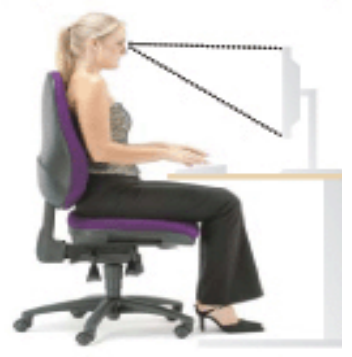

Figure 4 Upright Sitting Position

\section{Conclusion}

Since concentration is vital to learning and bad sitting position can lead to loss of concentration, we conclude that bad sitting in which the popularly acclaimed upright sitting position is one can negatively affect learning in the long run.
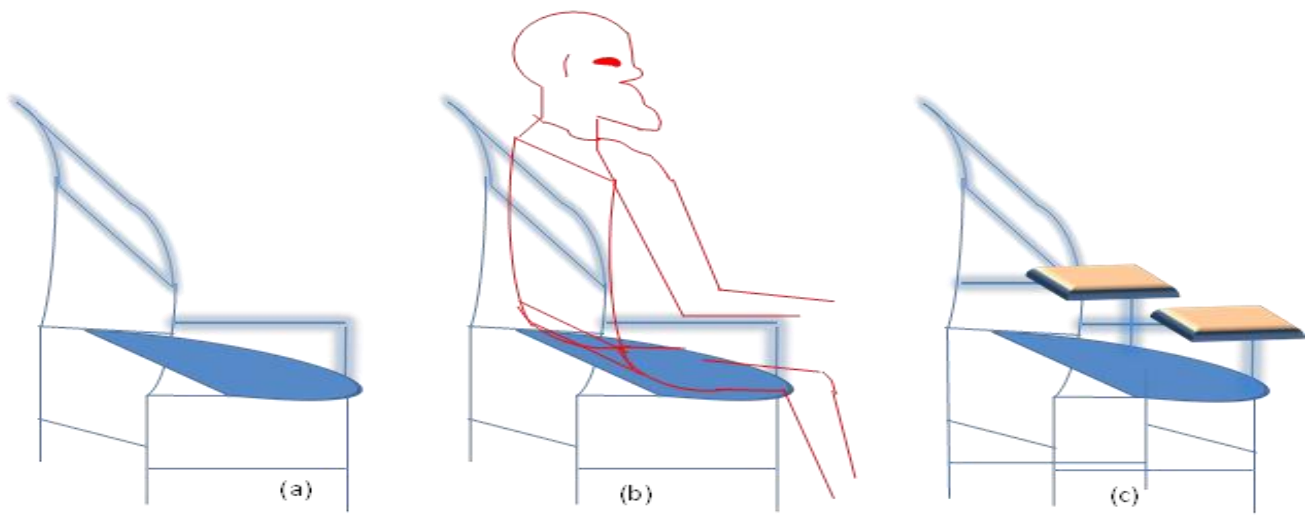

Figure 5

To achieve maximum sitting comfort, the seat must be design with:

1. Backrest supporting the dorso and the seat pan shifted a little as in figure 5a to enable a convex posture of the lumbar spine as in figure 5b. Also, seats should have armrest with the writing desk attach on the armrest as in figure 5c. This will also prevent neck pain which can result from leaning forward to write on the desk in front of the chair. For the purpose of variability in students' height, the armrest, seat height, armrest and seat pan should be made adjustable.

2. The backrest and the seat pan should have foam

\section{References}

[1]. Alexandra M., Urs F. and Terry H. 2006. 'Effects of Classroom Seating Arrangements on Children's question-asking'. Learning Environments Research 10-1999, Volume 2, Issue 3, pp 249-263 DOI10.1023/A:1009901922191

[2]. Arnsten, A. F. T. (2009). 'Stress signaling pathways that impair prefrontal cortex structure and function.' Nature Reviews Neuroscience 10 (6): 410-422. doi:10.1038/nrn264

[3]. Asai Shotokan; 'What part of your foot do you use when you turn?' Asai Shotokan Associatio International; Monthly Achieve 2013http://asaikarate.com/what-part-of-your-foot-do-you-use-when-you- Accessed 26-9-2013 
[4]. Belle Beth Cooper 2013; The Science of Posture: Sitting up straight will make you happier, more confident and less riskaverse;Better Social Media Management.http://blog.bufferapp.com/improve-posture-good-posture-science-happiness Accessed 33-2014

[5]. Brett Sear 2011;Proper Posture for the Low Back; Physical Therapy.http://physicaltherapy.about.com/od/backpain/a/ProperPosture-For-The-Low-Back.htm Accessed 3-3-2014.

[6]. Bruce S. McEwen, PhD., Rockefeller - University - See http://www.dana.org/Publications/ReportOnProgress/Effects_ofStress_on_the_Developing_Brain/\#sthash.et9wnSZ6.dpuf

[7]. Chair Clinic 2014, Sitting Correctly in Your Office Chair, http://www.chairclinic.co.uk/page/Sitting+Correctly Accessed 6-3-2014

[8]. Clapp, Jane (2006). Working on the Ball: A Simple Guide to Office Fitness. Andrews McMeel Publishing. ISBN 978-0-7407-56993.

[9]. CNC 2014; Five Factors That Contribute To A Good Learning Environment, Training materials for CNC,http://www.cncci.com/products/five\%20factors.htm Accessed 26-2-2014

[10]. Colorado Christian University (CCU) 2012.How Stress Affects Adult Students' Concentration;http://www.ccu.edu/blogs/cags/2012/01/how-stress-affects-adult-students-concentration/ Accessed 3-3-2014

[11]. Columbia University Graduate School of Arts \& Sciences Teaching Center (CUGSASTC) 2014;The Psychology of Learning and the Art of Teaching; http://www.columbia.edu/cu/tat/pdfs/psych_learning.pdf. Accessed 26-2-2014

[12]. Cornell University Ergonomics (CUE) 2014, Sitting and Chair Design http://ergo.human.cornell.edu/dea3250notes/sitting.html

[13]. Einas A., Syamala B. and Ganeswara R.M. 2013; 'Effect of Therapy Ball Seating on Learning and Sitting Discomforts among Saudi Female Students'; BioMed Research InternationalVolume 2013 (2013), Article ID 153165. http://dx.doi.org/10.1155/2013/153165

[14]. Eric R Kandel 2013, Thoughts, Dana Alliance Member News Volume XVIII • NO.1 http://www.dana.org/uploadedFiles/Pdfs/mbrnews_dec13.pdf

Hans Selye; Compare The Stress of Life, New York: McGraw-Hill, 1956.

[15]. Holly Heindselman, Rhemie Mentac, and Kristina Wesler, 2007. 'The Effect of Classroom Seating Arrangement on Learning Ability' Hanover CollegePSY 220: Research and Statistics.http://vault.hanover.edu/ altermattw/methods/assets/posterpics/Winter2007/Heindselman,Mentac,Wesler-w07.pdf Accessed 26-2-2014

[16]. Humphrey, J. H. (2005). Anthology of Stress Revisited: selected work of James H.Humphrey.Foreword by Paul J. Rosch. Nova Science Publishers. p. viii. ISBN 9781594546402. Retrieved 2014-02-21.

[17]. Jim flower 2006, "Factors that Influence Learning" http://jcflowers1.iweb.bsu.edu/rlo/factorslearning.htm. Accessed 26-2-2014

[18]. Karen Lynch 2011; 'How Sitting on a Ball Helps Kids Focus and Do Better In School';Gaiam Life. http://life.gaiam.com/article/how-sitting-ball-helps-kids-focus-and-do-better-school Accessed 26-2-2014.

[19]. Koolhaas, J., et al. "Stress revisited: A critical evaluation of the stress concept." Neuroscience

[20]. Leon N. Cooper 2013, Thoughts, Dana Alliance Member News Volume XVIII • NO. 1 http://www.dana.org/uploadedFiles/Pdfs/mbrnews_dec13.pdf

[21]. M.Y. Mafuyai et al.2013 ${ }^{\mathrm{a}}$, Reaction at the Inter-Vertebral Disc Due to Variation of Posture of Lumbar Spine and the Consequences on the Lower Back Pain. J. of Sciences and Multidisciplinary Research, Vol. 5, No. 2, Pp. $159-168$.

[22]. Mafuyai et al,2013 ${ }^{\mathrm{b}}$. 'The Increasing Cases of Low Back Pain in Developed Nations: A Reciprocal Effect of Development'. World Appl. Sci. J., 28 (9)

[23]. Mafuyai et al,2013'. 'Postural Theory of Non-Specific Low Back Pain (NSLBP)';World Appl. Sci. J., 28 (10): 1437-1443, 2013

[24]. Mafuyai et al,2014. 'Variation Of Lumbar Spine's Centre Of Mass With Changing Posture Of The Lumbar Spine'; Journal of Nigerian Association of Mathematical. Vol. 26(1) 257-266.

[25]. Melinda Smith, M.A., Robert Segal, M.A., and Jeanne Segal, Ph.D. Last updated: December 2013. www. Helpguide.com

[26]. McEwen, B. S.; Morrison, J. H. (2013). 'The Brain on Stress: Vulnerability and Plasticity of the Prefrontal Cortex over the Life Course. Neuron79 (1): 16-29. doi:10.1016/j.neuron.2013.06.028and Bio behavioral Reviews 35, 1291-1301, 2011

[27]. National Research Council (NRC)(2001). 'Musculoskeletal Disorders and the Workplace: Low Back and Upper Extremities'. Washington DC: The National Academic Press. National Academy Press. p. 512. ISBN 0-309-07284-0.

[28]. National Research Council (NRC)(1999). 'Work-Related Musculoskeletal Disorders: Report, Workshop Summary and Workshop Papers.National Academy Press. p. 240. ISBN 0-309-06397-3.

[29]. Occupational Safety and Health Administration (OSHA) 2014; Good Working Positions; United State Department of Labour.https://www.osha.gov/SLTC/etools/computerworkstations/positions.html Accessed 3-3-2014

[30]. Sondra C., Andy Z., Jack H., etal 2014; How to sit at computer; WikiHow.http://www.wikihow.com/Sit-at-a-Computer Accessed 3-3-2014

[31]. Stires, L. (1980). Classroom seating location, student grades, and attitudes: Environment or selfselection? Environment and Behavior, 12(2), 241-254.

[32]. Su Avasthi (2011);Don't Sit Up Straight: Why Good Posture Is Bad for Your Back; Gaiam Life http://life.gaiam.com/article/dontsit-straight-why-good-posture-bad-your-back Accessed 3-3-2014

[33]. Stanford Report, March 7, 2007 Robert Sapolsky discusses physiological effects of stress'We've evolved to be smart enough to make ourselves sick'

[34]. The Franklin Institute2014; Stress on the Brain;http://www.fi.edu/learn/brain/stress.html Accessed 22-2-2014.

[35]. United Nation Education, Scientific and Cultural organization (UNESCO) 2007,Enhancing learning; from access to success. Report of the first experts' meeting;Paris 26 to 28 March 2007.http://unesdoc.unesco.org/images/0015/001556/155642e.pdf Accessed 262-2014

[36]. University of Cambridge; University Counseling Services $\quad$ (USC) http://www.counselling.cam.ac.uk/selfhelp/leaflets/concentration Accessed 3-3-2014

[37]. Wen-Lan et al 2012, 'Influence of Therapy Ball Seats on Attentional Ability in Children with Attention Deficit/Hyperactivity Disorder'. J. of Phys. Ther. Sci. Vol. 24, No. 11, 2012 